\title{
Perinatal exposure of female rats to 2,3,7,8-tetrachlorodibenzo- $p$-dioxin induces central precocious puberty in the offspring
}

\author{
Masaki Kakeyama ${ }^{1,2}$, Hideko Sone ${ }^{2}$ and Chiharu Tohyama ${ }^{1,2}$ \\ ${ }^{1}$ Division of Environmental Health Sciences, Graduate School of Medicine, Center for Disease Biology and Integrative Medicine, The University of Tokyo, \\ 7-3-1 Hongo, Bunkyo-ku, Tokyo 113-0033, Japan \\ ${ }^{2}$ National Institute for Environmental Studies, Research Center for Environmental Risk, Tsukuba 305-8506, Japan \\ (Correspondence should be addressed to C Tohyama; Email: ctohyama@m.u-tokyo.ac.jp)
}

\begin{abstract}
Exposure to 2,3,7,8-tetrachlorodibenzo-p-dioxin (TCDD) during the fetal and neonatal periods has been indicated to alter the development of the offspring later in life. In this study, we determined whether perinatal exposure to a low dose of TCDD affects the onset of puberty in the female offspring of Long-Evans hooded rats. On day 15 of gestation, pregnant female rats were administered TCDD by gavage at a single dose of 0 (vehicle), 200, or $800 \mathrm{ng} / \mathrm{kg}$ b.w. In the female offspring born to dams administered with TCDD at either 200 or $800 \mathrm{ng} / \mathrm{kg}$ b.w., the vaginal opening and first estrus occurred 4-7 days earlier than in the offspring born to vehicle-treated animals. The ovarian weight gain was also accelerated following exposure to TCDD in a dose-dependent manner. We next examined the ovarian compensatory hypertrophy $(\mathrm{OCH})$ as an
\end{abstract}

indicator of the maturation of the LH/GnRH-generating system in the pituitary and the hypothalamus. Exposure to TCDD accelerated the onset of $\mathrm{OCH}$ in the female offspring in a dose-dependent manner. In particular, in the offspring born to the dams exposed to TCDD at $800 \mathrm{ng} / \mathrm{kg}$ b.w., hypertrophy, which is characterized by hyperovulation and a marked increase in the weight of the remaining ovary after hemi-ovariectomy, was observed on postnatal days $27-30$, which was 10 days earlier than in the offspring born to the vehicle-treated dams. These results indicate that perinatal exposure to a low dose of TCDD induces precocious puberty, including early maturation of the hypothalamic-pituitary axis, the gonads and genitals, in female Long-Evans hooded rats.

Journal of Endocrinology (2008) 197, 351-358

\section{Introduction}

Dioxin and its related compounds are a group of chemicals that are hazardous to man and wildlife, and their physical and chemical properties render them persistent not only in the environment but also in living organisms. Of the 200 kinds of congeners belonging to this group of chemicals, 2,3,7,8tetrachlorodibenzo- $p$-dioxin (TCDD) has been established as the most toxic congener, mainly because of its aryl hydrocarbon receptor-dependent mechanism, and has been used as a prototype in toxicological studies. TCDD is transferred transplacentally and lactationally to developing fetuses or neonates from their mothers and induces developmental impairments in the offspring, such as immunotoxicity, neurotoxicity, and reproductive toxicity as observed in laboratory animals, even when mothers are exposed to low levels of dioxins that do not affect themselves (Birnbaum \& Tuomisto 2000, Tohyama 2002, Schecter \& Gasiewicz 2003). In humans, accidental and environmental exposures to dioxins and related compounds have been suggested to cause some adverse effects in the offspring. The effects include learning deficits and abnormal play behavior as shown by Dutch cohort studies (Vreugdenhil et al. 2002, 2004), low intelligence quotients of inhabitants around Great Lake areas (Fields 2005), skewed sex ratio at birth as revealed by follow-up studies in Seveso, Italy (Mocarelli et al. 2000), and a very severe degree of reproductive and developmental toxicities in Yusho and Yucheng episodes as shown by Japanese and Taiwanese studies (Kuratsune et al. 1996, Guo et al. 1999).

To study the effects of perinatal exposure to TCDD on male and female offspring, the experimental protocol of a single oral administration of TCDD to pregnant rats has been widely used. An in utero and lactational exposure to TCDD, administered on gestational day (GD) 15 at a dose of $50-800 \mathrm{ng} / \mathrm{kg}$ b.w. was reported to induce disorders of the male reproductive organs (Mably et al. 1992, Ohsako et al. 2002), a decrease in epididymal sperm count (Gray et al. 1997a), and alteration of reproductive behavior in adulthood (Mably et al. 1992). An in vitro study (Lai et al. 2005) showed that TCDD modulates cAMP signaling in rat Leydig cells and affects the process of steroidogenesis. Female offspring, born to dams to which TCDD was administered at an oral dose of $1 \mu \mathrm{g} / \mathrm{kg}$ on GD15, was reported to show delayed vaginal opening (Gray et al. 1997b, Dienhart et al. 2000). However, in these studies, one cannot rule out the possibility that the delay observed might be attributable to the developmental delay and/or health impairment rather than 
a direct TCDD effect on sexual maturation, because the suppression of body weight gain and vaginal malformation were also observed. In addition, because sexual maturation is associated with not only the development of the external genitalia and ovaries, but also the luteinizing hormone (LH)/ gonadotropin-releasing hormone $(\mathrm{GnRH})$ surge-generating mechanism in the pituitary-hypothalamus, the possible effects of perinatal exposure to TCDD on the onset of puberty should be studied from a teratological aspect of the genitalia as well as from the entire aspect of sexual maturation. To clarify the effects of TCDD exposure on female sexual development and maturation, we studied the onset of vaginal opening (referred to as vaginal opening test hereafter), the development of the ovaries (referred to as ovarian development test hereafter), the onset of estrus cyclicity (referred to as estrus cyclicity test hereafter), and maturation of the hypothalamus-pituitary axis (referred also as first ovulation test and ovarian compensatory hypertrophy $(\mathrm{OCH})$ test hereafter) in offspring born to rats that were exposed to a low dose of TCDD, the level of which did not induce body weight loss of the offspring.

\section{Materials and Methods}

\section{Animals and treatments}

Long-Evans hooded rats were purchased and imported directly from Charles River Laboratories in Chicago, IL, USA. The administration of TCDD to animals and autopsies were performed in the specific hazardous chemicals controlled area of the National Institute for Environmental Studies (NIES). TCDD was purchased from Cambridge Isotope
Laboratory (Andover, MA, USA). The rats were perinatally exposed to TCDD, as described previously (Ohsako et al. 2002). Briefly, on GD15, pregnant female rats were administered TCDD by gavage $(2.5 \mathrm{ml} / \mathrm{kg})$ at $0(0 \cdot 1 \%$ nonane in corn oil as vehicle), 200, and $800 \mathrm{ng} / \mathrm{kg}$ b.w.; each group consisted of 16, 16, and 18 animals respectively. One day after birth, the number of male and female pups was adjusted, if possible, to five each per litter by culling, to minimize the variation in TCDD intake from dams' milk. Pups were weaned on postnatal day (PND) 21 and group-housed unisexually (four to five pups) thereafter $(78,80$, and 88 females in groups exposed to TCDD at 0, 200, and $800 \mathrm{ng} / \mathrm{kg}$ b.w.; hereafter referred to as 0-, 200-, and 800-TCDD-exposed groups respectively, as shown in Fig. 1). The body weights of the dams and pups were monitored daily throughout the experiment. Animals were handled with humane care according to the guidelines for animal experiments of the NIES. All data except for body weight gain were adjusted for litter membership to minimize maternal effects, and calculated using the average per litter as each representative value.

\section{Pubertal indicators}

The female offspring $(24,23$, and 25 animals (selected from 8, 8, and 9 litters respectively, to minimize litter effects) of the 0 -, 200-, and 800-TCDD-exposed groups respectively) were monitored daily in the morning by the vaginal opening test (Fig. 1). Once vaginal opening was observed, the first estrus and the estrus cyclicity were determined by the daily monitoring of vaginal smear as the first estrus test (Fig. 1). Vaginal estrus was considered to have occurred when cornified epithelial cells

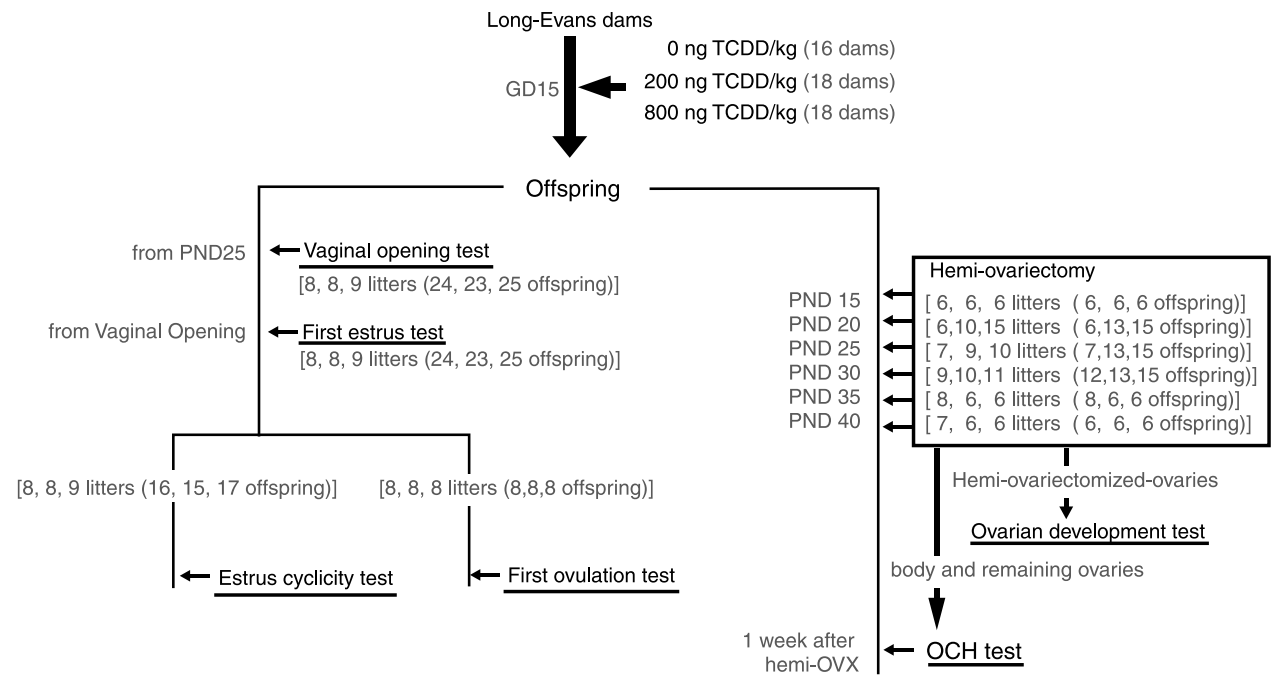

Figure 1 Experimental scheme for the study of the effects of perinatal exposure to 2,3,7,8,-tetrachlorodibenzop-dioxin (TCDD) on puberty of female Long-Evans hooded rats. Dams were exposed to TCDD at 0, 200, or 800 ng/kg b.w. (0-, 200-, and 800-TCDD-exposed groups respectively, hereafter) on gestational day 15, and offspring were divided into two groups for two experimental series. A group of offspring was used for the vaginal opening test from PND 25, followed by tests for the first estrus, estrus cyclicity, and first ovulation. The other group was used for the $\mathrm{OCH}$ test and the ovarian development test after hemi-ovariectomy. The figures in parentheses indicate the number of animals used in each group. 
became the major component of the smear. When the normal duration of the estrus cycle was found to be repeated at least three times by monitoring the vaginal smear from each group of rats, the estrus cyclicity was determined by the estrus cyclicity test (Fig. 1). From each group, eight rats, each selected from eight litters, were killed under diethyl ether anesthesia in the morning when the first vaginal estrus was observed, and the number of ova in the oviduct was counted as first ovulation test (Fig. 1). All animals were killed at specified times at a maximum of PND 64 to collect ovaries and uteri.

\section{OCH test}

A specified number of animals in the TCDD-exposed groups were subjected to hemi-ovariectomy under light diethyl ether anesthesia on PNDs 15, 20, 25, 30, 35, and 40 (6-15 litters per group, see details in Fig. 1). The remaining ovary was harvested on the day when the estrus phase was detected by smear test in the morning of days 7-10 after hemi-ovariectomy. In case the estrus phase was not detected during this 4-day period, the remaining ovary was harvested on day 10 . The harvested ovary was weighed and examined histopathologically, as described below, for OCH test. The number of ova in the oviduct was counted at P25 (hemi-ovariectomy on PND 15 and OCH test on PNDs 23-25), P30 (hemi-ovariectomy on PND 20 and OCH test on PNDs 27-30), P35 (hemi-ovariectomy on PND 25 and $\mathrm{OCH}$ test on PNDs 33-35), P40 (hemi-ovariectomy on PND 30 and OCH test on PNDs 37-40), P45 (hemiovariectomy on PND 35 and $\mathrm{OCH}$ test on PNDs 42-45), and P50 (hemi-ovariectomy on PND 40 and $\mathrm{OCH}$ test on PNDs 47-50). The $\mathrm{OCH}$ in this experiment indicates the estimated percentage of $\mathrm{OCH}$ (estimated $\mathrm{OCH} \%$ ) that was derived from the following equation: (remaining ovarian weight/expected ovarian weight) $\times 100$. The expected ovarian weight of each animal was determined using a regression curve of ovarian development in each exposed group (Fig. 3). The equations for regression curve for the $0 \mathrm{ng} \mathrm{TCDD} / \mathrm{kg}$ group, $200 \mathrm{ng} \mathrm{TCDD} / \mathrm{kg}$ group, and $800 \mathrm{ng} \mathrm{TCDD} / \mathrm{kg}$ group are $Y=483 \mathrm{e}^{0 \cdot 0457 X}$ with $R^{2}=0.937, Y=6 \cdot 18 \mathrm{e}^{0 \cdot 042 X}$ with $R^{2}=0.954$, and $Y=23.6 \ln (X)-51.4$ with $R^{2}=0.931$ respectively. $X$ and $Y$ represent the day of $\mathrm{OCH} \%$ test and the expected ovarian weight respectively, when hemi-ovariectomy was not performed.

\section{Ovarian development test}

To examine ovarian development, the ovary on the right side was removed from each animal during a specific developmental period. The remaining left ovary enlarged to compensate the ovary function, i.e. $\mathrm{OCH}$ as described above. The current experimental design enabled us to collect ovary samples to examine the effect of TCDD exposure on ovarian development on PNDs 15, 20, 25, 30, 35, and 40 (see Fig. 1). All these collected ovary samples were weighed and histopathologically examined as described below.

\section{Histological examination}

For histological examinations, the organs were weighed, fixed in Bouin's solution, embedded in paraffin, sectioned at $5 \mu \mathrm{m}$ thickness throughout the organ and stained with hematoxylin and eosin. Every fifth section, was examined for the presence of follicles and corpora lutea in the ovary by light microscopy.

\section{Statistical analysis}

All statistical analyses were performed using SPSS 16.0 software (SAS Japan Inc., Tokyo, Japan). A difference was considered statistically significant at $P<0 \cdot 05$. In statistical analyses, data for the incidence of ovulation and the presence of corpora lutea in the ovary were analyzed by the $\chi^{2}$-test. Other data were analyzed by one-way ANOVA followed by Scheffe's post hoc test, while body and ovarian weight gains were analyzed by either two-way or repeated-measures two-way ANOVA. Data were expressed as mean \pm s.E.M. unless otherwise stated.

\section{Results}

\section{Neonatal and maternal data}

Following the administration of TCDD to the pregnant rats at a single oral dose of 200 and $800 \mathrm{ng} / \mathrm{kg}$ b.w., no significant

Table 1 Body weight gain after perinatal exposure to 2,3,7,8,-tetrachlorodibenzo- $p$-dioxin (TCDD) in Long-Evans hooded rats

\begin{tabular}{|c|c|c|c|}
\hline & $\mathbf{0}$ (8 litters) & 200 (8 litters) & $\mathbf{8 0 0}$ (9 litters) \\
\hline \multicolumn{4}{|c|}{ TCDD exposure (ng/kg b.w. $)^{a}$} \\
\hline PND 0 & $5 \cdot 9 \pm 0 \cdot 2$ & $6 \cdot 0 \pm 0 \cdot 2$ & $6 \cdot 1 \pm 0 \cdot 2$ \\
\hline PND 7 & $15 \cdot 4 \pm 0 \cdot 7$ & $15 \cdot 3 \pm 0 \cdot 7$ & $15 \cdot 3 \pm 0 \cdot 6$ \\
\hline PND 14 & $32 \cdot 3 \pm 1 \cdot 1$ & $32 \cdot 0 \pm 1 \cdot 2$ & $31 \cdot 8 \pm 0 \cdot 9$ \\
\hline PND 21 & $54 \cdot 5 \pm 2 \cdot 2$ & $54 \cdot 0 \pm 2 \cdot 0$ & $55 \cdot 1 \pm 2 \cdot 2$ \\
\hline PND 28 & $87 \cdot 6 \pm 2 \cdot 6$ & $86 \cdot 8 \pm 2 \cdot 5$ & $86 \cdot 0 \pm 2 \cdot 8$ \\
\hline PND 35 & $132 \cdot 5 \pm 3 \cdot 3$ & $129 \cdot 1 \pm 3 \cdot 5$ & $127 \cdot 2 \pm 3 \cdot 7$ \\
\hline PND 42 & $166 \cdot 0 \pm 4 \cdot 0$ & $163 \cdot 5 \pm 3 \cdot 9$ & $159 \cdot 2 \pm 4 \cdot 4$ \\
\hline PND 49 & $193 \cdot 6 \pm 3 \cdot 7$ & $185 \cdot 2 \pm 4 \cdot 0$ & $177 \cdot 7 \pm 3 \cdot 8^{*}$ \\
\hline
\end{tabular}

$* P<0 \cdot 05$ versus the 0-exposed group, by ANOVA. Data were adjusted for litter membership to minimize maternal effects.

a Dams were exposed to TCDD at 0, 200, or $800 \mathrm{ng} / \mathrm{kg}$ b.w. (0-, 200-, and 800-TCDD-exposed groups respectively, hereafter) on gestational day 15 . 
physiological gross alterations were observed in dams and pups: these alterations refer to body weight gain during pregnancy, maternal death, number of live pups, and birth weight of pups (data not shown). A slight decrease in body weight gain was observed on PND 49 in the 800-TCDDexposed group $(P<0 \cdot 05)$, whereas there were no difference between groups from PND 0 to 42 (Table 1).

\section{Vaginal opening and ovarian development}

The day of vaginal opening in each female offspring was monitored to determine the maturation of the external genitalia by the vaginal-opening test. In the female rats of the 0-TCDD-exposed group, vaginal opening was found to occur on PND $36.6 \pm 1.9$ (Table 2), which was similar to observations in previous studies using Long-Evans hooded rats (Rayner et al. 2004, Salazar et al. 2004). In comparison with the control offspring rats, TCDD accelerated the onset of vaginal opening in the offspring of the 200- and 800-TCDD-exposed groups in a dose-dependent manner, and vaginal opening was observed on PNDs $33 \cdot 3 \pm 1 \cdot 8$ and $29 \cdot 1 \pm 1 \cdot 8$ respectively.

For the analysis of ovarian development, the right-side ovaries were collected from PND 15 to 40 at a 5-day interval. In the control offspring, the ovarian weight gain was $25 \cdot 2 \%$, from $11 \cdot 1 \pm 0.9 \mathrm{mg}$ on PND 15 to $13.8 \pm 1.0 \mathrm{mg}$ on PND 25, followed by a $210 \%$ increase to $29 \cdot 6 \pm 2 \cdot 1 \mathrm{mg}$ on PND 40 (Fig. 2). Perinatal exposure of dams to TCDD accelerated ovarian development of their female pups in a dose-dependent manner. Ovarian weight increased sharply from PND 20 to 25; the weights were $17 \cdot 9 \pm 1 \cdot 3$ and $28 \cdot 6 \pm 2 \cdot 2 \mathrm{mg}$ on PND 25 in the offspring of the 200- and 800-TCDD-exposed groups respectively. The ovarian weights of the offspring of the 200 - and 800-TCDD-exposed groups were significantly higher than those of the offspring of the corresponding 0-TCDD-exposed group on PNDs 25,30 , and $35(P<0 \cdot 01$ in the 200-TCDDexposed group and $P<0 \cdot 001$ in the 800-TCDD-exposed group versus the 0-TCDD-exposed group). Owing to a catch up by the offspring of the 0-TCDD-exposed group, no significant difference in ovarian weight was found between these groups on PND 40 (Fig. 2).

Table 2 Onset of vaginal opening and first estrus after perinatal exposure to 2,3,7,8,-tetrachlorodibenzo-p-dioxin (TCDD) in LongEvans hooded rats

\begin{tabular}{|c|c|c|c|c|}
\hline & $\begin{array}{l}\text { Vaginal } \\
\text { opening } \\
\text { day }\end{array}$ & $\begin{array}{l}\text { First } \\
\text { estrus } \\
\text { day }\end{array}$ & $\begin{array}{l}\text { Number } \\
\text { of litters }\end{array}$ & $\begin{array}{l}\text { Number } \\
\text { of animals }\end{array}$ \\
\hline \multicolumn{5}{|c|}{ TCDD exposure (ng/kg b.w.) $)^{a}$} \\
\hline 0 & $36 \cdot 6 \pm 1 \cdot 9$ & $40 \cdot 6 \pm 2 \cdot 2$ & 8 & 24 \\
\hline 200 & $33 \cdot 3 \pm 1 \cdot 8$ & $35 \cdot 9 \pm 3 \cdot 4$ & 8 & 23 \\
\hline 800 & $29 \cdot 1 \pm 1 \cdot 8^{*}$ & $32 \cdot 7 \pm 2 \cdot 2^{*}$ & 9 & 25 \\
\hline
\end{tabular}

$* P<0.05$ versus the 0 -exposed group, by ANOVA. Data were adjusted for litter membership to minimize maternal effects.

${ }^{a}$ Dams were exposed to TCDD at 0, 200, or $800 \mathrm{ng} / \mathrm{kg}$ b.w. $(0-, 200-$, and 800 -TCDD-exposed groups respectively, hereafter) on gestational day 15 (for vaginal-opening and first estrus tests, see the legend of Fig. 1).

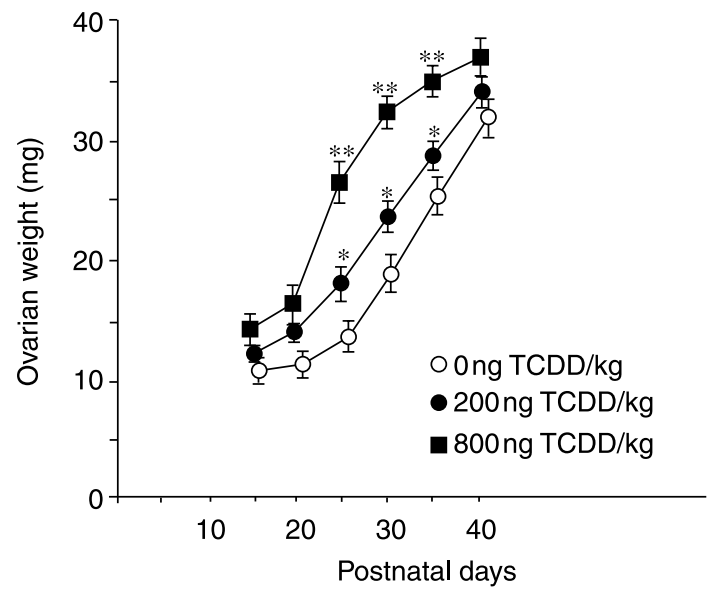

Figure 2 Effects of perinatal exposure to 2,3,7,8,-tetrachlorodibenzo-p-dioxin (TCDD) on ovarian weight gain of rats. Each point is expressed as the mean \pm s.E.M. for $6-15$ litters, which were taken from animals subjected to hemi-ovariectomy. $* P<0 \cdot 01$ versus the 0 -TCDD- or 800-TCDD-exposed group; ${ }^{* *} P<0 \cdot 001$ versus the 0 -TCDD-exposed group (for ovarian development test, see the legend of Fig. 1).

A histopathological examination revealed that the female offspring of the 0-TCDD-exposed group had ovaries with many Graafian follicles by PND 35 (all seven offspring) but no corpora lutea were found until PND 40 (Table 3, Fig. 3). By contrast, the ovaries of the offspring of the 200- and 800TCDD-exposed groups showed Graafian follicles by PNDs 25 and 20 respectively. On PND 30, seven out of ten litters (10 out of 13 animals) of the 200-TCDD-exposed group, and all 15 litters (15 animals) of the 800 -exposed dams showed corpora lutea $(P<0 \cdot 001$; Table 3, Fig. 3).

First estrus, first ovulation, and estrus cyclicity

First estrus test The onset of the first estrus was determined by the daily vaginal smear monitoring. The onset of the first estrus in the female offspring of the 0-TCDD-exposed group was PND $40 \cdot 6 \pm 2 \cdot 2$ (Table 2). By contrast, perinatal exposure to TCDD at 200 and $800 \mathrm{ng} / \mathrm{kg}$ b.w. was found to accelerate the onset of the first estrus of the offspring, namely PNDs $35 \cdot 9 \pm 3 \cdot 4$ and $32 \cdot 7 \pm 2 \cdot 2$ respectively, in a dose-dependent manner, with a statistically significant difference for the 800-TCDD-exposed group $(P<0 \cdot 01$ versus the 0 -TCDD-exposed group, Table 2).

First ovulation test When ovulation at the first estrus was examined, five out of eight female rats born to vehicle-treated dams ovulated at the first estrus on PND 40.0 $\pm 1 \cdot 7$, ranging from PND 37 to 42 . All the rats born to dams treated with TCDD at 200 or $800 \mathrm{ng} / \mathrm{kg}$ b.w. ovulated at the first estrus on PNDs 34-38 and PNDs 29-33 respectively. No significant difference in the number of ova was found among the animals ovulated $(13 \cdot 2 \pm 2 \cdot 2,13 \cdot 9 \pm 2 \cdot 1$, and $14 \cdot 2 \pm 2 \cdot 4$, in the $0-, 200-$, and 800-TCDD-exposed groups respectively). 
Table 3 Number of litters showing corpora lutea after perinatal exposure to 2,3,7,8,-tetrachlorodibenzo-p-dioxin (TCDD) in Long-Evans hooded rats

TCDD exposure (ng/kg b.w.) $)^{\mathrm{a}}$

PND15

PND20

PND25

PND30

PND35

PND40
0

0/6 $(0 / 6)^{b}$
$0 / 6(0 / 6)$
$0 / 7(0 / 7)$
$0 / 9(0 / 12)$
$0 / 8(0 / 8)$
$6 / 6(6 / 6)$

200

$0 / 6(0 / 6)$

$0 / 10(0 / 13)$

$0 / 9(0 / 13)$

$7 / 10 *(10 / 13)$

$6 / 6 *(6 / 6)$

$6 / 6(6 / 6)$
800

$0 / 6(0 / 6)$

$0 / 15(0 / 15)$

$0 / 10(0 / 15)$

$15 / 15^{*}(15 / 15)$

$6 / 6^{*}(6 / 6)$

$6 / 6(6 / 6)$

${ }^{*} P<0.05$ versus the 0 -exposed group, by $\chi^{2}$-test.

${ }^{a}$ Dams were exposed to TCDD at 0, 200 or $800 \mathrm{ng} / \mathrm{kg}$ b.w. (0-, 200- and 800-TCDD-exposed groups respectively, hereafter) on gestational day 15 (for ovarian development test, see the legend of Fig. 1).

${ }^{b}$ Value inside the parenthesis shows the data as number of offspring of each group.

Estrus cyclicity test When we examined whether perinatal exposure to TCDD affected the estrus cycle of these offspring $(8,8$, and 9 litters in the vehicle group, 200-TCDD-exposed group and 800-TCDD-exposed group respectively), all the rats showed an estrus cycle of 4 or 5 days, and no abnormal estrus cyclicity was observed since they had the first estrus.

\section{OCH test}

In the control offspring born to vehicle-treated dams, $\mathrm{OCH}$ was not observed until P40 (hemi-ovariectomy was performed on PND 30 and the $\mathrm{OCH}$ was examined on PNDs 37-40, as described in the Materials and Methods). No ovulation was observed on P25 (data not shown) and P30 (Fig. 4A), and the $\mathrm{OCH} \%$ values were only $102 \cdot 0 \pm 15 \cdot 6 \%$ and $102 \cdot 5 \pm 12 \cdot 1 \%$ respectively (Fig. 4B). Only one out of seven litters (2 out of 12 offspring) born to vehicle-treated dams ovulated, and the average number of ova in the ovulating animals were 5.5 (five and six each) on P35. On P40, seven out of the nine control litters, which comprises 10 out of 12 offspring respectively, hyperovulated $(10 \cdot 9 \pm 2 \cdot 4$ ova from the remaining ovary, $P<0 \cdot 001$ versus the 0 -TCDD-exposed group without hemiovariectomy of $\mathrm{P} 40,6 \cdot 6 \pm 2 \cdot 0$ ova per ovary), and the $\mathrm{OCH} \%$ values were $212 \pm 15 \%$ (Fig. $4 \mathrm{~A}$ and $\mathrm{B}$ ).

In the offspring of the 200-TCDD-exposed group, hypertrophy was observed as early as P35 and the mean number of ova of the ovulating animals was $9 \cdot 5 \pm 1 \cdot 2$. Six out of the nine litters, which comprises 8 out of 13 offspring respectively, showed a significantly greater number of ova during this period than the vehicle-treated group $(P<0 \cdot 05$, Fig. 4A). The $\mathrm{OCH} \%$ on P35 of the offspring of the $200-$ TCDD-exposed group was $160 \pm 17 \%$, which is significantly higher than that of the control offspring born to vehicletreated dams $(P<0 \cdot 005$, Fig. 4B). In the offspring of the $800-$ TCDD-exposed group, hypertrophy was observed as early as P30. During this period, the mean number of ova detected in the oviduct of ovulating animals was $12 \cdot 9 \pm 1 \cdot 7$, and 12 out of 151 , which comprises 12 out of 15 offspring respectively, had a significantly greater number of ova than the control

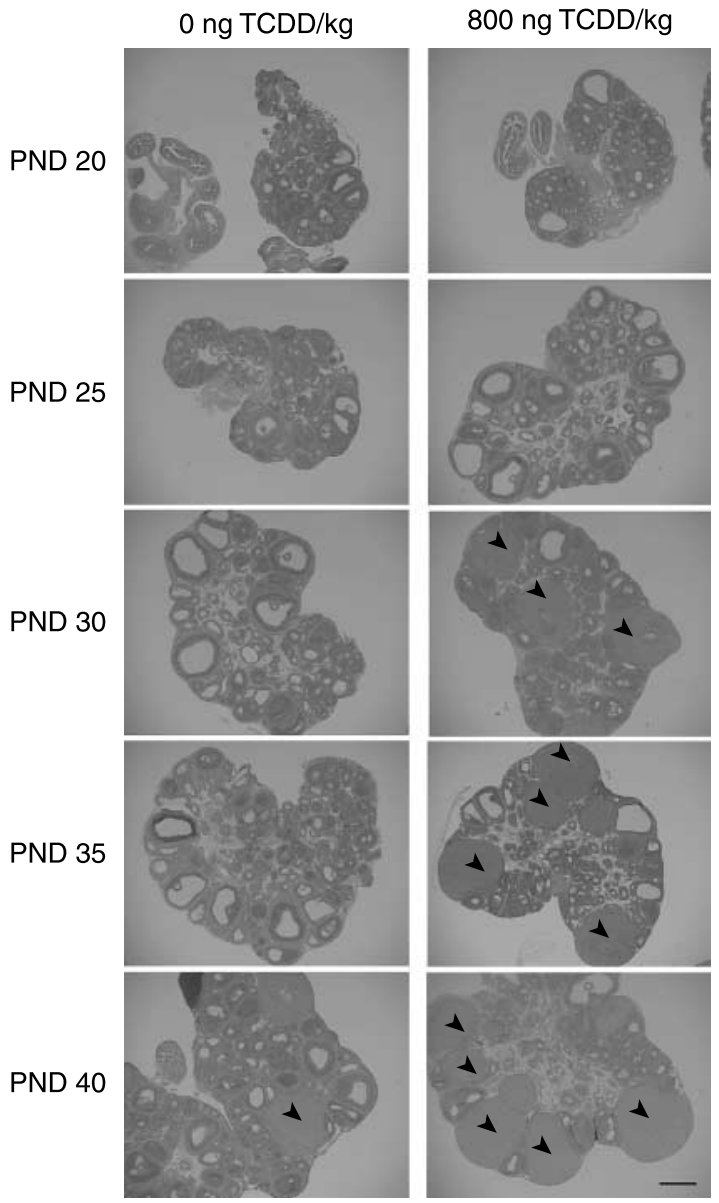

Figure 3 Representative transverse sections of ovaries from rat offspring, on PNDs 20-40, of 0- and 800-TCDD-exposed groups. Corpora lutea (arrowheads) were observed from PND 30 in the $800 \mathrm{ng} / \mathrm{kg}$ TCDD-exposed animals, whereas they were not observed until PND 40 in the vehicle-treated animals. Hematoxylin and eosin; scale bar $=500 \mu \mathrm{m}$ (for ovarian development test, see the legend of Fig. 1). 
offspring of the 0-TCDD-exposed group $(P<0 \cdot 001$, Fig. 4A). The $\mathrm{OCH} \%$ of the $800-\mathrm{TCDD}$-exposed group was $219 \pm 16 \%$ on P30 when compared with that of the 0 -TCDD-exposed group $(P<0 \cdot 001$, Figs $4 \mathrm{~B}$ and 5$)$.

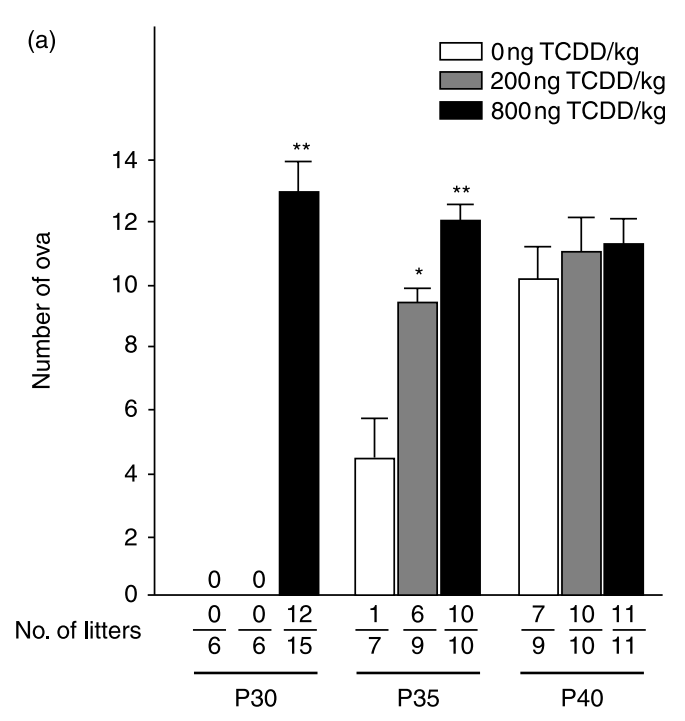

(b)

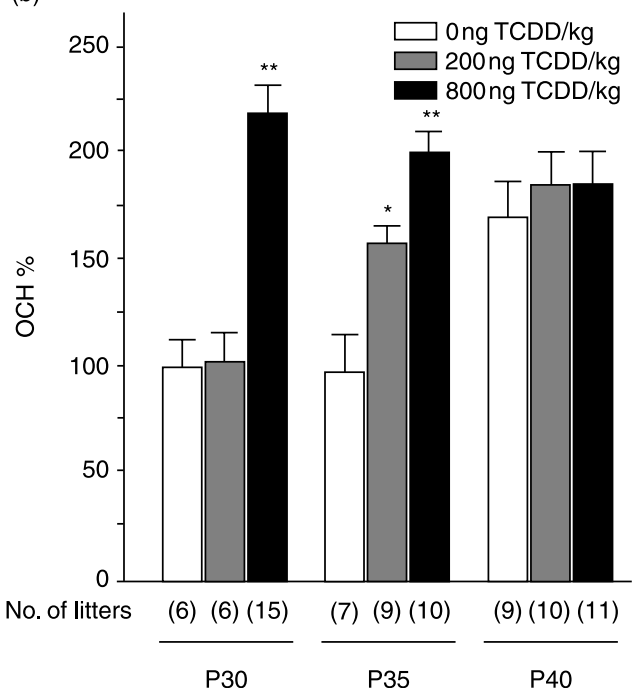

Figure 4 Effects of perinatal exposure to 2,3,7,8,-tetrachlorodibenzo-p-dioxin (TCDD) on ovarian compensatory hypertrophy $(\mathrm{OCH})$ in rats, shown as $(\mathrm{A})$ the number of ova and $(\mathrm{B})$ estimated percentage of $\mathrm{OCH}$ 7-10 days after hemi-ovariectomy. Each bar represents mean \pm s.E.M. P25, hemi-ovariectomy on PND 15 and $\mathrm{OCH}$ on PNDs 23-25; P30, hemi-ovariectomy on PND 20 and $\mathrm{OCH}$ on PNDs 27-30; P35, hemi-ovariectomy on PND 25 and $\mathrm{OCH}$ on PNDs 33-35; P40, hemi-ovariectomy on PND 30 and OCH on PNDs 37-40; P45, hemi-ovariectomy on PND 35 and $\mathrm{OCH}$ on PNDs 42-45; P50, hemi-ovariectomy on PND 40 and OCH on PNDs 47-50. $* P<0 \cdot 005$ and $* * P<0 \cdot 001$ indicate a significant difference from the offspring born to vehicle-treated dams (for $\mathrm{OCH}$ test, see the legend of Fig. 1).

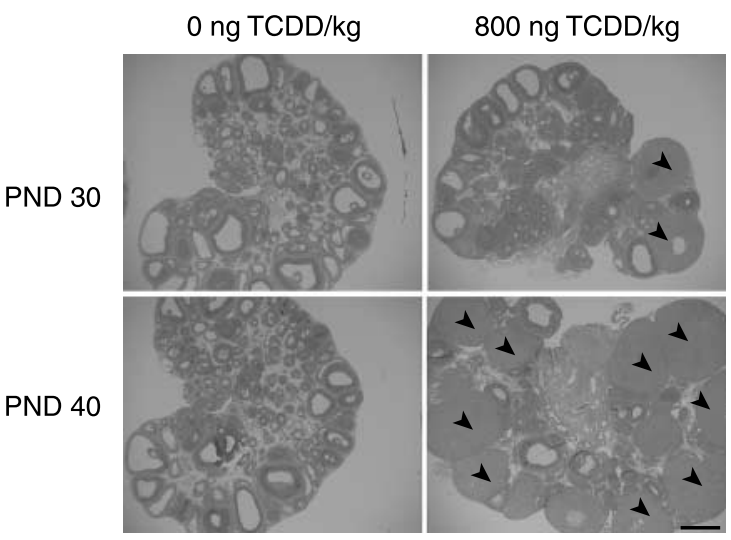

Figure 5 Representative transverse sections of the remaining ovary 10 days after hemi-ovariectomy in the control and 2,3,7,8,tetrachlorodibenzo-p-dioxin (TCDD)-exposed (800 ng/kg b.w.) groups. Many corpora lutea (arrowheads) were observed in the TCDD-exposed group. No corpora lutea was observed in the control group by P40 (hemi-ovariectomy on PND 30 and the $\mathrm{OCH}$ was examined on PNDs 37-40) (for OCH test, see the legend of Fig. 1).

\section{Discussion}

Dioxin and its related compounds have attracted much attention owing to their widespread contamination worldwide and their marked toxicity particularly in the offspring of laboratory animals at the level of sub-microgram per kilogram body weight, which is far less than that of most of the chemicals present in the environment. In this study, we report three novel findings. First, in utero and lactational exposure of Long-Evans hooded rats to a low dose of TCDD induces early onset of puberty in female offspring, which is in contrast to the results of a previous study (Gray et al. 1997b), in that TCDD administered orally to dams at a dose of $1 \mu \mathrm{g} / \mathrm{kg}$ body weight during gestation caused a delay in vaginal opening. The delay in vaginal opening found in the previous study may be attributable to peripheral toxicity, as suggested by the finding of a vaginal thread, a kind of terata, and a decrease in the body weight of neonates (Gray et al. 1997b, Dienhart et al. 2000). By contrast, no such anomalies and no significant decrease in body weight were found in neonates in our present and previous studies (Kakeyama et al. 2001, 2003). In the present experiment, low doses of TCDD without these peripheral anomalies induced precocious puberty, being attributable to the brain as described below. The utilization of a high dose in the 'toxic' range may confer data very different from those of studies on 'endocrine disruption' effects mediated at very low doses of the given chemical.

Second, TCDD causes central precocious puberty by affecting the brain and not by the peripheral organs. This hypothesis is supported by the present experimental evidence revealing that TCDD-exposed animals showed early onset of ovulation and estrus cyclicity, which are governed by the GnRH-generating system in the brain (Mitsushima et al. 2003, Odum et al. 2004, Pinyerd \& Zipf 2005). On the other hand, 
peripheral precocious puberty, which is typically observed as early genital and somatic development, occurs independent of brain maturation (Mitsushima et al. 2003), but is not associated with early ovulation and estrus cyclicity. It is widely accepted that peripheral precocious puberty cannot induce the early ovulation and the early onset of estrus cyclicity (Partsch et al. 2002). To verify the TCDD-induced early maturation of the GnRH-generating system in the brain, we examined the onset of OCH during the developmental period as a new index of the maturation of the hypothalamus-pituitary-genital axis, as described in the following paragraph.

Third, the onset of compensatory hypertrophy during the prepubertal period was shown to be a new useful index for the sexual maturation of the brain. The $\mathrm{OCH} \%$ is calculated on the basis of the removed ovarian weight at the time of hemi-ovariectomy (Fukuda et al. 1984, Baligar \& Kaliwal 2004). However, this method could not be directly applied to our present experiment because ovarian weight showed a marked increase during the developmental period, and because we could not preclude the possibility that TCDD itself affected ovarian development. Thus, in this study, we developed a method of obtaining an estimated $\mathrm{OCH} \%$ using a minimum number of animals, and the expected ovarian weight was determined on an individual animal basis, by calculating from the regression curve of ovarian development for each exposed group (Fig. 3). Thus, the estimated $\mathrm{OCH} \%$ in this study represents the effects of hemi-ovariectomy on the occurrence of OCH itself. Thus, the data at the time of hemiovariectomy in the $\mathrm{OCH}$ study allowed us to estimate ovarian development in the present experiment, including the theoretical curve of ovarian weight gain. There has been theoretical and experimental background knowledge on the $\mathrm{OCH}$. Since the concept of the $\mathrm{OCH}$ phenomenon was first proposed nearly half a century ago (Mandl et al. 1952), experimental evidence has accumulated. When rats were hemi-ovariectomized, the remaining ovary showed compensatory hypertrophy with a twofold increase in its weight as well as hyperovulation, and this phenomenon was considered to be induced by an increase in the secretion of gonadotropins and/or direct neural regulation via vagus nerves (Chavez et al. 1987). The right side of the medial anterior hypothalamus is considered to be responsible for predominantly regulating $\mathrm{OCH}$, because a unilateral lesion placed in the right side, but not in the left side of this region suppresses $\mathrm{OCH}$ (Fukuda et al. 1984). The maturation of the hypothalamus, ovary and pituitary are prerequisites for the onset of $\mathrm{OCH}$, indicating that the negative feedback of estrogen and the GnRH-surge secretion cooperatively functions. Thus, the onset of $\mathrm{OCH}$ can be an excellent index for the maturation of the hypothalamus.

Because the aryl hydrocarbon receptor (AhR) is ubiquitously distributed in various brain regions including the hypothalamus (Petersen et al. 2000), and TCDD enters and distributes in the brain tissue from the blood circulation (Kakeyama et al. 2003), it is reasonable to speculate that TCDD affects the GnRH surge-generating mechanism and elicits its toxicity by activating the AhR pathway. Other studies showed that TCDD distributed at the CNS exerts neurotoxicological effects: a high TCDD dose $(10 \mu \mathrm{g} / \mathrm{kg})$ administered to rats was shown to reduce $\mathrm{LH}$ secretion and the number of ova at ovulation (Petroff et al. 2001). Exposure to TCDD at $15 \mu \mathrm{g} / \mathrm{kg}$ was reported to decrease the neuropeptide $\mathrm{Y}$ level in the arcuate nucleus (Fetissov et al. 2004) that is presumably involved in ovulation (Estrada et al. 2003) and the sexual maturation of the hypothalamus (Kalra \& Kalra 2004). We reported in our previous study (Kakeyama et al. 2001) that the in utero and lactational exposure of rat dams to TCDD resulted in the alteration of the N-methyl-D-aspartate (NMDA) receptor subunit mRNA expression in the brain of their offspring. Because NMDA receptors are involved in the maturation of the brain GnRH surge-generating mechanisms (Kanamaru et al. 2001), it is reasonable to speculate that an alteration in the NMDA neural transmission induced by TCDD during development is, at least in part, responsible for the TCDD-induced central precocious puberty. Further studies are required to clarify this point.

\section{Acknowledgements}

The authors thank Dr Fred Vom Saal (University of Missouri) for his critical reading of this manuscript. This work was supported in part by a CREST grant from JST (to C T), and a grant for Research on Food and Chemical Safety from the Ministry of Health, Labour and Welfare (to C T), and a grantin-aid from the Japan Society for the Promotion of Sciences (to $\mathrm{C} \mathrm{T}$ ), and an LRI research grant from the Japan Chemical Industry Association (to M K). The authors declare that there is no conflict of interest that would prejudice the impartiality of the results.

\section{References}

Baligar PN \& Kaliwal BB 2004 Carbofuran induced block of compensatory ovarian growth in hemicastrated albino mice. Toxicology 204 87-95.

Birnbaum LS \& Tuomisto J 2000 Non-carcinogenic effects of TCDD in animals. Food Additives and Contaminants 17 275-288.

Chavez R, Cruz ME \& Dominguez R 1987 Differences in the ovulation rate of the right or left ovary in unilaterally ovariectomized rats: effect of ipsiand contralateral vagus nerves on the remaining ovary. Journal of Endocrinology 113 397-401.

Dienhart MK, Sommer RJ, Peterson RE, Hirshfield AN \& Silbergeld EK 2000 Gestational exposure to 2,3,7,8-tetrachlorodibenzo- $p$-dioxin induces developmental defects in the rat vagina. Toxicological Sciences 56 141-149.

Estrada KM, Pompolo S, Morris MJ, Tilbrook AJ \& Clarke IJ 2003 Neuropeptide Y (NPY) delays the oestrogen-induced luteinizing hormone (LH) surge in the ovariectomized ewe: further evidence that NPY has a predominant negative effect on LH secretion in the ewe. Journal of Neuroendocrinology 15 1011-1020.

Fetissov SO, Huang P, Zhang Q, Mimura J, Fujii-Kuriyama Y, Rannug A, Hokfelt T \& Ceccatelli S 2004 Expression of hypothalamic neuropeptides after acute TCDD treatment and distribution of Ah receptor repressor. Regulatory Peptides 119 113-124.

Fields S 2005 Great lakes: resource at risk. Environmental Health Perspectives 113 A164-A173. 
Fukuda M, Yamanouchi K, Nakano Y, Furuya H \& Arai Y 1984 Hypothalamic laterality in regulating gonadotropic function: unilateral hypothalamic lesion and ovarian compensatory hypertrophy. Neuroscience Letters $\mathbf{5 1}$ 365-370.

Gray LE, Ostby JS \& Kelce WR 1997a A dose-response analysis of the reproductive effects of a single gestational dose of 2,3,7,8-tetrachlorodibenzo- $p$-dioxin in male Long Evans Hooded rat offspring. Toxicology and Applied Pharmacology 146 11-20.

Gray LE, Wolf C, Mann P \& Ostby JS 1997b In utero exposure to low doses of 2,3,7,8-tetrachlorodibenzo- $p$-dioxin alters reproductive development of female Long Evans hooded rat offspring. Toxicology and Applied Pharmacology 146 237-244.

Guo YL, Yu ML, Hsu CC \& Rogan WJ 1999 Chloracne, goiter, arthritis, and anemia after polychlorinated biphenyl poisoning: 14-year follow-up of the Taiwan Yucheng cohort. Environmental Health Perspectives 107 715-719.

Kakeyama M, Sone H \& Tohyama C 2001 Changes in expression of NMDA receptor subunit $\mathrm{mRNA}$ by perinatal exposure to dioxin. Neuroreport 12 4009-4012

Kakeyama M, Sone H, Miyabara Y \& Tohyama C 2003 Perinatal exposure to 2,3,7,8-tetrachlorodibenzo- $p$-dioxin alters activity-dependent expression of BDNF mRNA in the neocortex and male rat sexual behavior in adulthood. Neurotoxicology 24 207-217.

Kalra SP \& Kalra PS 2004 NPY - an endearing journey in search of a neurochemical on/off switch for appetite, sex and reproduction. Peptides 25 465-471.

Kanamaru H, Kakeyama M, Seki T \& Arai Y 2001 Estrogen potentiates $N$-methyl-D-aspartate receptor subunit R2B mRNA expression during the late prepubertal period in female rats. Neuroscience Letters 300 9-12.

Kuratsune M, Yoshimura H, Hori Y, Okumura M \& Masuda Y 1996 Yusho: A Human Disaster Caused by PCBs and Related Compounds. Fukuoka: Kyushu University Press.

Lai KP, Wong MH \& Wong CK 2005 Inhibition of CYP450scc expression in dioxin-exposed rat Leydig cells. Journal of Endocrinology 185 519-527.

Mably TA, Moore RW, Goy RW \& Peterson RE 1992 In utero and lactational exposure of male rats to 2,3,7,8-tetrachlorodibenzo-p-dioxin. 2. Effects on sexual behavior and the regulation of luteinizing hormone secretion in adulthood. Toxicology and Applied Pharmacology 114 108-117.

Mandl AM, Zuckerman S \& Patterson HD 1952 The number of oocytes in ovarian fragments after compensatory hypertrophy. Journal of Endocrinology 8 347-356.

Mitsushima D, Tin Tin Win S \& Kimura F 2003 Sexual dimorphism in the GABAergic control of gonadotropin release in intact rats. Neuroscience Research 46 399-405.

Mocarelli P, Gerthoux PM, Ferrari E, Patterson DG Jr, Kieszak SM, Brambilla P, Vincoli N, Signorini S, Tramacere P, Carreri V et al. 2000 Paternal concentrations of dioxin and sex ratio of offspring. Lancet 355 1858-1863.
Odum J, Tinwell H, Tobin G \& Ashby J 2004 Cumulative dietary energy intake determines the onset of puberty in female rats. Environmental Health Perspectives 112 1472-1480.

Ohsako S, Miyabara Y, Sakaue M, Ishimura R, Kakeyama M, Izumi H, Yonemoto J \& Tohyama C 2002 Developmental stage-specific effects of perinatal 2,3,7,8-tetrachlorodibenzo- $p$-dioxin exposure on reproductive organs of male rat offspring. Toxicological Sciences 66 283-292.

Partsch CJ, Heger S \& Sippell WG 2002 Management and outcome of central precocious puberty. Clinical Endocrinology 56 129-148.

Petersen SL, Curran MA, Marconi SA, Carpenter CD, Lubbers LS \& McAbee MD 2000 Distribution of mRNAs encoding the arylhydrocarbon receptor, arylhydrocarbon receptor nuclear translocator, and arylhydrocarbon receptor nuclear translocator-2 in the rat brain and brainstem. Journal of Comparative Neurology 427 428-439.

Petroff BK, Roby KF, Gao X, Son D, Williams S, Johnson D, Rozman KK \& Terranova PF 2001 A review of mechanisms controlling ovulation with implications for the anovulatory effects of polychlorinated dibenzo- $p$ dioxins in rodents. Toxicology 158 91-107.

Pinyerd B \& Zipf WB 2005 Puberty-timing is everything!. Journal of Pediatric Nursing 20 75-82.

Rayner JL, Wood C \& Fenton SE 2004 Exposure parameters necessary for delayed puberty and mammary gland development in Long-Evans rats exposed in utero to atrazine. Toxicology and Applied Pharmacology 195 23-34.

Salazar V, Castillo C, Ariznavarreta C, Campon R \& Tresguerres JA 2004 Effect of oral intake of dibutyl phthalate on reproductive parameters of Long Evans rats and pre-pubertal development of their offspring. Toxicology 205 $131-137$.

Schecter A \& Gasiewicz TA 2003 Dioxins and Health. New Jersey: John Wiley $\&$ Sons Inc.

Tohyama C 2002 Low-dose exposure to dioxin. Its toxicities and health risk assessment. Environmental Sciences 9 37-50.

Vreugdenhil HJ, Slijper FM, Mulder PG \& Weisglas-Kuperus N 2002 Effects of perinatal exposure to PCBs and dioxins on play behavior in Dutch children at school age. Environmental Health Perspectives 110 A593-A598.

Vreugdenhil HJ, Mulder PG, Emmen HH \& Weisglas-Kuperus N 2004 Effects of perinatal exposure to PCBs on neuropsychological functions in the Rotterdam cohort at 9 years of age. Neuropsychology 18 185-193.

\section{Received in final form 25 February 2008}

Accepted 3 March 2008

Made available online as an Accepted Preprint 3 March 2008 